\title{
Response to Commentaries: Life History Genetics, Fluid Intelligence, and Extended Phenotypes
}

\author{
Severi Luoto ${ }^{1,2}$ \\ Published online: 6 February 2019 \\ (C) Springer Nature Switzerland AG 2019
}

Dixson (2019) contextualizes, qualifies, and extends the research and ideas I presented in a recent article on extended phenotypes, human sexual selection, and life history theory (Luoto 2019). He notes that since age at first intercourse has a significant genetic component, genetic factors may influence the cross-national association between adolescent fertility and economic complexity. Dixson (2019) calls for further genetically informed research on extended phenotypes.

To offer a preliminary response to this research call, I collected data on the national life history strategy genetic factor index from Minkov and Bond (2015) and compared it with economic complexity and adolescent fertility rates. ${ }^{1}$ The androgen receptor gene AR, the dopamine receptor gene DRD4, and the 5-HTTLPR VNTR of the serotonin transporter gene have been associated with national variation in life history outcomes and time orientation (Minkov and Bond 2015, and references therein). Following Minkov and Bond (2015), national scores on the life history strategy genetic factor index were defined by average AR CAG repeat length, DRD4 $7+8$ allele frequency, and 5-HTTLPR Sallele frequency. The national life history strategy genetic factor index was significantly correlated with the Economic Complexity Index $\left(r_{s}=.51, p<.001, n=52\right.$, Fig. 1$)$. As expected, countries with a "slower" life history genetic factor index had higher economic complexity. The genetic factor index was also significantly correlated with adolescent fertility rates $\left(r_{s}=-.57, p<.0001, n=52\right){ }^{2}$ Countries with a "faster" life history genetic factor index had higher adolescent fertility rates, as expected.

Building on prior research (Figueredo et al. 2004; Minkov and Bond 2015; van der Linden et al. 2018), these results indicate that life history strategies and more proximal

\footnotetext{
${ }^{1}$ The genetic factor index consists of data on 52 countries (Minkov and Bond 2015). Data on Economic Complexity Index (The Atlas of Economic Complexity 2017) and adolescent fertility rates (UN Statistics Division 2017) are subsets ( $n=52)$ of the dataset used in Luoto (2019).

${ }^{2}$ Spearman's rank correlation coefficient was used in these analyses because of non-normal distribution of data for the life history genetic factor index and adolescent fertility rates.
}

Severi Luoto

s.luoto@auckland.ac.nz

1 English, Drama and Writing Studies, University of Auckland, Auckland 1010, New Zealand

2 School of Psychology, University of Auckland, Auckland 1010, New Zealand 


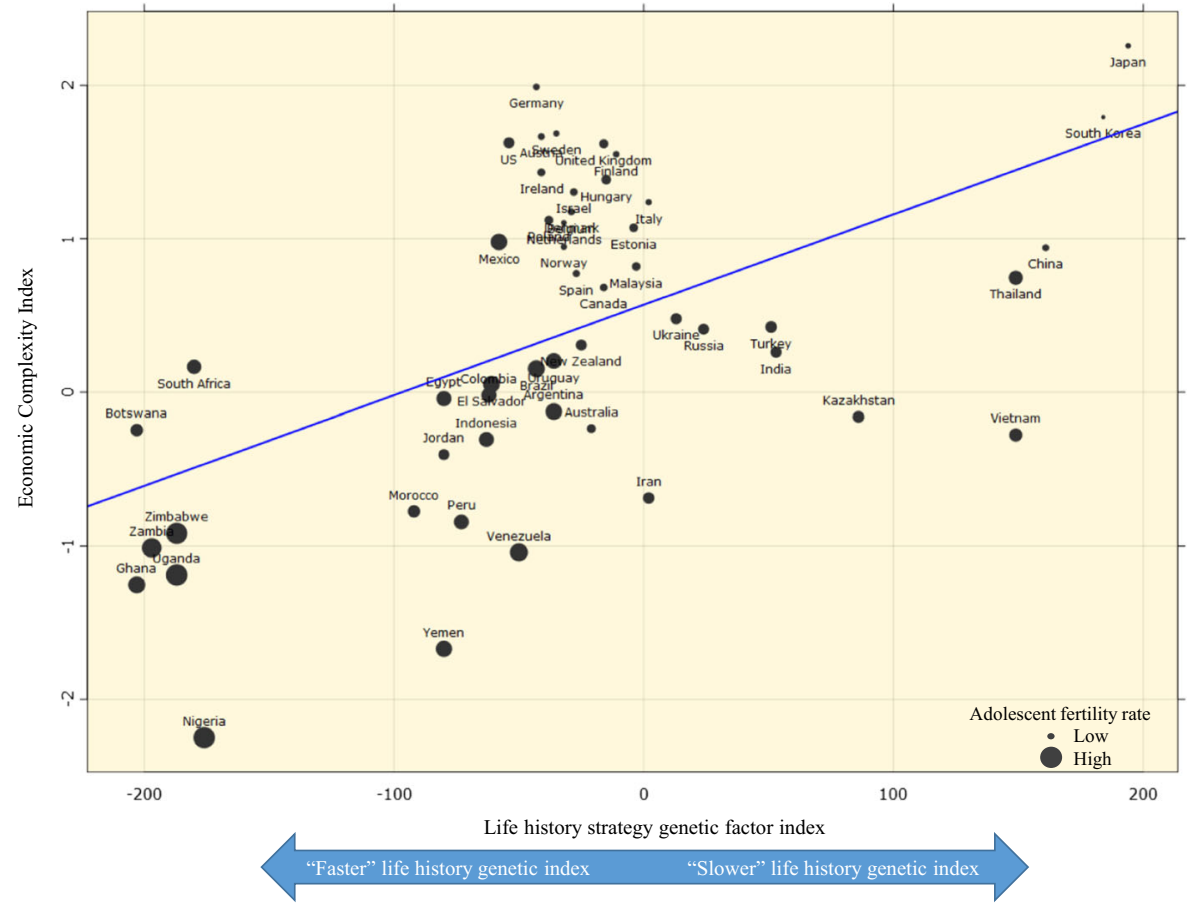

Fig. 1 A positive relationship between the national life history strategy genetic factor index and Economic Complexity Index $\left(r_{s}=.51, p<.001, n=52\right)$. A low value on the genetic factor index indicates a genetic predisposition for faster life history strategies (Minkov and Bond 2015). Data points are scaled per countryspecific adolescent fertility rate (calculated as births per 1000 women ages 15-19: min. = 1.66 in South Korea, max. $=114.85$ in Uganda, $M=34.27, S D=30.23$ )

behavioral outcomes such as economic complexity can have a significant genetic component. Dixson (2019) notes that a genetic confound could reflect non-adaptive mutational drift rather than localized responses to competing life history processes. Future research may reveal the extent to which these findings represent random mutations or whether they constitute directional selection based on local ecologies (Luoto 2019).

Dixson calls into question the empirical validity and theoretical utility of the sexual strategies theory (Buss and Schmitt 2019), suggesting that it "may not be relevant to understanding how sexual selection has shaped male investment in phenotypic extensions" (Dixson 2019). Dixson cites studies on facial masculinity preferences to support his argument. However, viewing morphed faces on a computer screen, with shoulders and the rest of the body cropped out, is hardly an ecologically valid mate choice scenario. Actual mate choice zeroes in on a range of phenotypic, behavioral, and extended phenotypic traits over a long time period (Luoto 2019; Miller and Todd 1998). Recent evidence also indicates that facial masculinity is not a conditiondependent male ornament and does not reflect MHC heterozygosity (Zaidi et al. 2019). It therefore appears that Dixson (2019) prematurely rejects the sexual strategies framework based on facial morphometric studies. Sexual strategies theory is supported in various ways by other evidence from anthropological and psychobehavioral studies (Arslan et al. 2019; Buss and Schmitt 2019; Flegr et al. 2019; Scelza and Prall 2018) that have higher ecological validity than the facial morphometrics research paradigm. A 
careful evaluation of the extended phenotype theory (Luoto 2019) reveals that it does not hinge upon women's preferences for facial masculinity in any meaningful way.

Dinh and Gangestad (2019) provide additional questions to direct future research on the role of extended phenotypes in human sexual selection. They correctly point out that most extended phenotypes that may influence human sexual selection are unlikely to do so via specialized psychological adaptations for evaluating those particular traits. Dinh and Gangestad (2019) note that evolved mate choice adaptations that take into account extended phenotypic productions "must be capable of extracting information that is represented at a level that would have been recurrent during the period in which the adaptations evolved". Importantly, however, this is not how evolved psychological mechanisms work (Al-Shawaf et al. 2019). Evolutionarily novel extended phenotypic traits can be cues (not evolved signals) of underlying characteristics, and humans are cognitively sophisticated enough to associate such novel cues with desirable phenotypic and/or genotypic characteristics in potential mates. Evolved psychological mechanisms are not inflexible: they are highly context-sensitive, requiring environmental input at every stage of their emergence (Al-Shawaf et al. 2019).

A significantly fluid component in Homo sapiens intelligence enables humans to assess evolutionarily and situationally novel traits that inform overall mate value evaluations. Humans regularly apply fluid intelligence to make rational decisions, overcoming more rudimentary motivational forces by using higher-order cognitive processing (Duncan et al. 2017; Kenrick et al. 2010; Yang et al. 2019). Thus, the degree to which extended phenotypes exploit sensory biases, constitute sensory traps (such as pets and food gifts) (Luoto 2019), or evoke higher-order cognitive processes to evaluate distal traits (Luoto 2017; Miller and Todd 1998) is a question for future research to explore. None of these scenarios presupposes the existence of functionally specific evolved cognitive mechanisms for appraising specific modern traits such as cars and apartments.

I offered a broad overview of extended phenotype theory and applied it in crosscultural analyses of innovation and economic complexity (Luoto 2019). Future research can now focus on any aspect of the complex interrelationships between ecology, genetics, human life histories, sexual selection, and extended phenotypes, including those emphasized by Dixson (2019) and Dinh and Gangestad (2019). Zooming in (Krams et al. 2019; Luoto and Rantala 2018) and out (Luoto 2019; Luoto et al. 2019) between various levels of analysis can be immensely valuable when researching complex topics such as human evolution and its present-day behavioral manifestations.

Acknowledgements The author is grateful for Peter K. Jonason's comments on an earlier draft of this article.

Funding This work was supported by the Emil Aaltonen Young Researcher Grant.

\section{Compliance with Ethical Standards}

Conflicts of Interest The author declares that the research was conducted in the absence of any commercial or financial relationships that could be construed as a potential conflict of interest.

Publisher's Note Springer Nature remains neutral with regard to jurisdictional claims in published maps and institutional affiliations. 


\section{References}

Al-Shawaf, L., Lewis, D. M. G., Wehbe, Y. S., \& Buss, D. M. (2019). Context, environment, and learning in evolutionary psychology. In: Shackelford, T. \& Weekes-Shackelford, V. A. (Eds.). Encyclopedia of Evolutionary Psychological Science. Springer, Cham.

Arslan, R. C., Schilling, K. M., Gerlach, T. M., \& Penke, L. (2019). Using 26 thousand diary entries to show ovulatory changes in sexual desire and behaviour. Journal of Personality and Social Psychology, (in press).

Buss, D. M., \& Schmitt, D. P. (2019). Mate preferences and their behavioral manifestations. Annual Review of Psychology, 70, 77-110. https://doi.org/10.1146/annurev-psych-010418-103408.

van der Linden, D., Dutton, E., \& Madison, G. (2018). National-level indicators of androgens are related to the global distribution of scientific productivity and science Nobel prizes. The Journal of Creative Behavior.https://doi.org/10.1002/jocb.351.

Dinh, T. \& Gangestad, S. W. (2019). On the underlying cognitive adaptations for extended phenotype expression and evaluation. Adaptive Human Behavior and Physiology.

Dixson, B. J. (2019). Sexual selection and extended phenotypes in humans. Adaptive Human Behavior and Physiology. https://doi.org/10.1007/s4075.

Duncan, J., Chylinski, D., Mitchell, D. J., \& Bhandari, A. (2017). Complexity and compositionality in fluid intelligence. Proceedings of the National Academy of Sciences, 114, 5295-5299. https://doi.org/10.1073 /pnas.1621147114.

Figueredo, A. J., Vásquez, G., Brumbach, B. H., \& Schneider, S. M. (2004). The heritability of life history strategy: The k-factor, covitality, and personality. Social Biology, 51, 121-143.

Flegr, J., Blum, A. E., Nekola, O., \& Kroupa, Š. (2019). What people prefer and what they think they prefer in short-and long-term partners. The effects of the phase of the menstrual cycle, hormonal contraception, pregnancy, and the marital and the parenthood status on partner preferences. Evolution and Human Behavior, 40, 112-125. https://doi.org/10.1016/j.evolhumbehav.2018.09.003.

Kenrick, D. T., Griskevicius, V., Neuberg, S. L., \& Schaller, M. (2010). Renovating the pyramid of needs: Contemporary extensions built upon ancient foundations. Perspectives on Psychological Science, 5, 292-314.

Krams, I., Luoto, S., Rubika, A., Krama, T., Elferts, D., Kecko, S., Skrinda, I., Moore, F., Krams, R., \& Rantala, M. J. (2019). A head start for life history development? Family income mediates associations between body height and immune response in men. American Journal of Physical Anthropology. https://doi.org/10.1002/ajpa.23754.

Luoto, S. (2017). Commentary: Beauty requires thought. Frontiers in Psychology, 8, 1281. https://doi. org/10.3389/fpsyg.2017.01281.

Luoto, S. (2019). An updated theoretical framework for human sexual selection: From ecology, genetics, and life history to extended phenotypes. Adaptive Human Behavior and Physiology, 1-55. https://doi. org/10.1007/s40750-018-0103-6.

Luoto, S., \& Rantala, M. J. (2018). On estrogenic masculinization of the human brain and behavior. Hormones and Behavior, 97, 1-2. https://doi.org/10.1016/j.yhbeh.2017.07.017.

Luoto, S., Krams, I., \& Rantala, M. J. (2019). A life history approach to the female sexual orientation spectrum: Evolution, development, causal mechanisms, and health. Archives of Sexual Behavior, 1-36. https://doi.org/10.1007/s10508-018-1261-0.

Miller, G. F., \& Todd, P. M. (1998). Mate choice turns cognitive. Trends in Cognitive Sciences, 2, 190-198.

Minkov, M., \& Bond, M. H. (2015). Genetic polymorphisms predict national differences in life history strategy and time orientation. Personality and Individual Differences, 76, 204-215.

Scelza, B. A., \& Prall, S. P. (2018). Partner preferences in the context of concurrency: What Himba want in formal and informal partners. Evolution and Human Behavior, 39, 212-219.

The Atlas of Economic Complexity (2017). Country Complexity Rankings. Internet database. Available at: http://atlas.cid.harvard.edu/rankings/ Retrieved on December 6, 2017.

UN Statistics Division (2017). World Development Indicators 2014. Internet database. Available at: http://data. un.org/Default.aspx. Retrieved on December 20, 2017.

Yang, G. R., Joglekar, M. R., Song, F., Newsome, W. T., \& Wang, X. J. (2019). Task representations in neural networks trained to perform many cognitive tasks. Nature Neuroscience. https://doi.org/10.1038/s41593018-0310-2.

Zaidi, A. A., White, J. D., Mattern, B. C., Liebowitz, C. R., Puts, D. A., Claes, P., \& Shriver, M. D. (2019). Facial masculinity does not appear to be a condition-dependent male ornament in humans and does not reflect MHC heterozygosity. Proceedings of the National Academy of Sciences, 201808659. https://doi. org/10.1073/pnas.1808659116. 